\title{
An investigation into contracted loaded tip propellers using computational fluid dynamics (CFD)
}

\author{
N R J Williams* BEng (hons) SIMarEST \\ * Southampton University, UK \\ * Corresponding Author Email: nick0796@hotmail.co.uk
}

\begin{abstract}
Synopsis
This paper investigates the potential performance improvements of adding contracted loaded tips to propellers. A Wageningen B5-75 Series propeller has been simulated and verified against published experimental test data. Contracted tips have then been added to a Wageningen propeller and the modified propeller then simulated. A CFD method and model has been developed. Pressure, velocity and vector plots have all been analysed detailing the mechanism behind the contracted tips. Limitations behind this method have been explored and explained, and recommendations for further studies made. The development of a database of propeller characteristics and performance chart data to allow quick evaluation of designs has also been proposed.
\end{abstract}

Keywords: Propeller; CFD; Contracted Loaded Tip; Wageningen;

\section{Introduction}

Over $90 \%$ of the world's cargo is transported by the shipping industry using more than 50,000 vessels (International Chamber of Shipping). With today's concerns about the environment there is a real focus in improving the efficiency of ships and reducing the carbon footprint of shipping. Regulations such as MARPOL Annex VI issued by the International Maritime Organization (IMO) require newly designed ships to be more efficient than ever before. One of the main rules is the Energy Efficiency Design Index (EEDI) that covers mandatory technical and operational energy efficiency measures, aimed at reducing greenhouse gas emissions from ships (International Maritime Organization, 2011). For ship designers to comply with this rule, they need to embrace new technology and more efficient designs. One way of improving a ship's efficiency is through its propulsion mechanism. The majority of ships around the world use propellers (MAN Diesel \& Turbo, 2011) and an increase in propeller efficiency can help a ship comply with the regulations and potential future rules. For older ships, a retrofit for a more efficient propeller can help reduce the amount of fuel used by a vessel that in turn can reduce both the environmental and economic cost of transporting goods around the world.

In this investigation, Contracted Loaded Tips (CLT) have been studied as a performance enhancing feature of a propeller. To achieve this, a Wageningen B Series propeller was modified to have contracted tips. An open water test of the original propeller was simulated using computational fluid dynamics (CFD) and validated against experimental test results. The CLT propeller was also simulated under the same conditions. The performance changes and the mechanism behind the contracted tips have been studied using the simulated Wageningen propeller as a baseline case. The limitations of the simulation have been highlighted and recommendations for further studies made.

The Wageningen B-Series propeller is a standard series propeller with approximately 120 propellers ranging from 2-7 blades. It is known as one of the most widely used propeller series in scale model testing (Carlton, 2007). The experimental tests for the series were first carried out in 1936 performed by the Netherlands Ship Model Basin. Many people have studied Wageningen propellers, the most comprehensive study was completed by Lammeren in 1969. The Wageningen series experiments have spanned a period of more than 30 years and have been simulated in CFD in multiple papers (Prakash and Nath, 2012; Beng Yeo et al., 2014; Nguyen and Ikeda, 2015). It was chosen due to its popularity and availability of the blade geometry data and experimental results.

A contracted loaded tip propeller (CLT) is a unique design that puts endplates on the end of propeller blades to improve performance and efficiency (see Figure 1). They have been used on more than 280 vessels around the world (Gonzalez-Adalid and Gennaro, 2009) and are "the most efficient widespread type of unconventional propeller" (Gennaro, 2006). Performance improvements over conventional propellers of up to 3-4\% have been recorded (Gonzalez-Adalid and Gennaro, 2009).

Nick Williams is currently studying an MSc in Maritime Engineering Science / Marine Engineering at the University of Southampton and has recently completed a summer placement at BMT Defence and Security. He completed his undergraduate degree, BEng (hons) Marine Technology, at the University of Plymouth including an industrial placement year at Condor Ferries. 
CLT propellers are characterised by the following (Gennaro, 2006):

- Pitch increasing monotonic from blade root to tip

- Finite chord at tip

- End plate fitted at the blade tip towards the pressure side

- Low to moderate skew

The endplates on the propeller act as a barrier preventing the water on each side of the blade from "communicating" (this is where water from the face and back of the blade meet at the tip of the propeller), it is the interaction between the negative pressure on the suction face of the blade (the blade back) and the positive pressure face (the blade front) that generate the tip vortices (SISTEMAR, 2018). An increased negative pressure on the back of a blade increases the likelihood of cavitation (Carlton, 2007), contracted tips can reduce the negative pressure and improve the cavitation performance. The tips also increase the pressure on the front of the blades resulting in an increased thrust produced and an improved overall open water efficiency over a conventional propeller (Gennaro, 2006). The endplates also prevents the flow on the face of the blades from escaping radially outwards (Gennaro, 2006). Several CFD studies have been completed into CLT propellers however they all use structured meshing (Gaggero et al., 2016b; Bertetta et al., 2012; Gaggero et al., 2016a; Brown et al., 2014) and managed to simulate open water tests with reasonable accuracy compared with experimental test data.

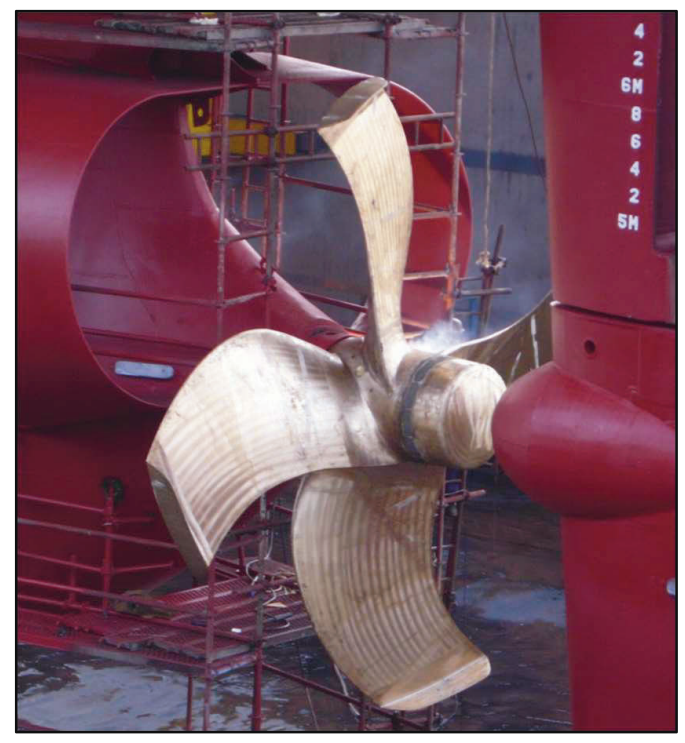

Figure 1 - A contracted loaded tip propeller on a 35000DWT tanker (Gennaro and GonzalesAdalid, 2012)

\section{Methodology}

\subsection{CFD Analysis Procedure}

The following procedure has been followed for the CFD investigation:

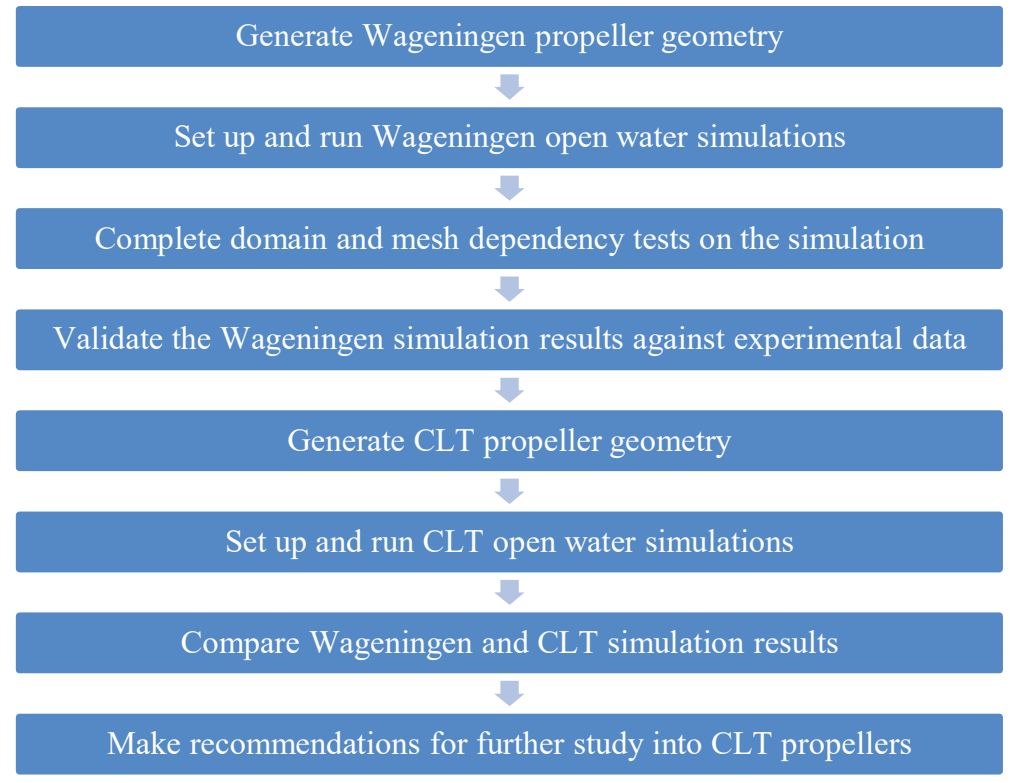

Figure 2-CFD analysis procedure flow chart 


\subsection{Propeller Geometry}

The Wageningen B-Series propeller was used as the CFD validation case. The geometry of the propeller blade has been generated using the method summarised below, Table 1 shows the propeller's geometry parameters. The propeller diameter has been specified as $0.24 \mathrm{~m}$, this is the same size as the propellers in the Wageningen tests. This allows the results from the simulation to be directly compared with the experiment with no requirement to account for scale effects (all the test conditions are the same in the CFD to the experiment).

Table 1 - Propeller geometry parameters

\begin{tabular}{ll}
\hline Parameter & Value \\
\hline Diameter $(\mathrm{D})$ & $0.24 \mathrm{~m}$ \\
\hline Number of blades $(\mathrm{Z})$ & 5 \\
\hline Blade area ratio $\left(\boldsymbol{A}_{\boldsymbol{E}} / \boldsymbol{A}_{\mathbf{0}}\right)$ & 0.75 \\
\hline Pitch to diameter ratio $(\mathrm{P} / \mathrm{D})$ & 0.8 \\
\hline Hub diameter $(\mathbf{d})$ & $0.04 \mathrm{~m}$ \\
\hline Rake Angle $\left(\boldsymbol{\theta}_{\mathrm{R}}\right)$ & $15^{\circ}$ \\
\hline
\end{tabular}

\subsubsection{Wageningen Blade Profile}

The Wageningen propeller's blade geometry has been defined in "Further Computer-Analyzed Data of the Wageningen B-Screw Series" (Oosterveld and Van Oossanen, 1975). From this data, the coordinates of blade profiles at varying radii have been generated. The coordinates of the profiles were then manipulated using mathematical translations to add skew, pitch, rake, and curvature in that order (see Figure 3 and Figure 4 for a visual representation of the translations). Once these translations were performed, the coordinates were imported into a CAD programme (SOLIDWORKS in this case) and the propeller was modelled. A parametric spreadsheet in EXCEL was developed for generating blade shape data for five-seven bladed Wageningen propellers.

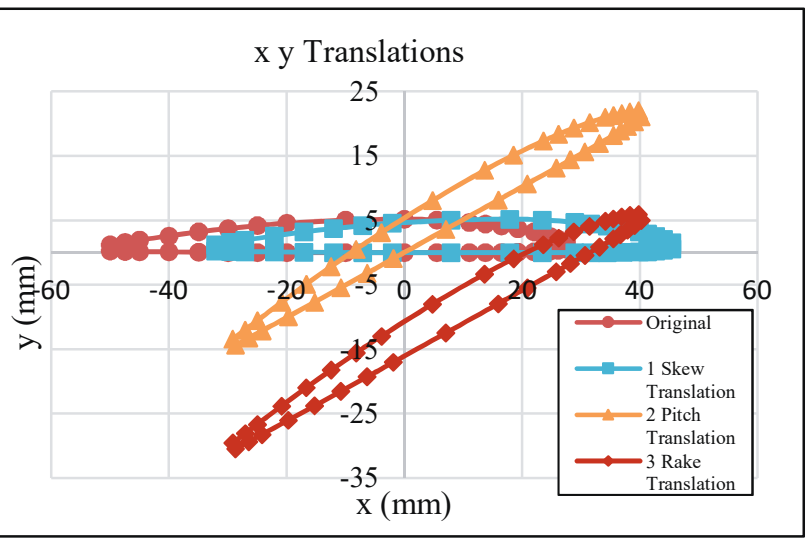

Figure 3 - Graph showing translations performed in the xy plane to the blade profile coordinates

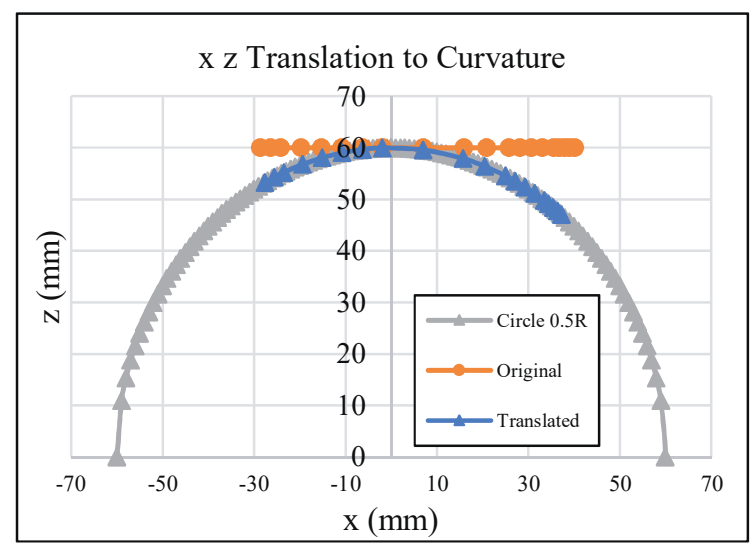

Figure 4 - Graph showing translation adding curvature in the xz plane to the blade profile coordinates 
Figure 5 shows the curves of the blades at each radius. The surfaces are filleted with a radius of $0.5 \mathrm{~mm}$ (the total blade thickness is $1 \mathrm{~mm}$ ). This creates the trailing and leading edges of the blade (see Figure 6). Fillets have been added because the meshing software fails to mesh to a finite point with a reasonable quality mesh.

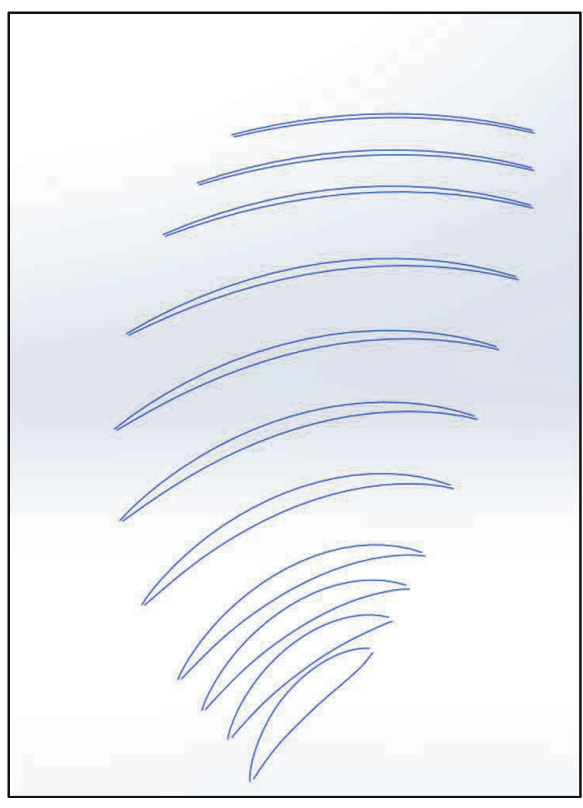

Figure 5 - Imported blade profiles

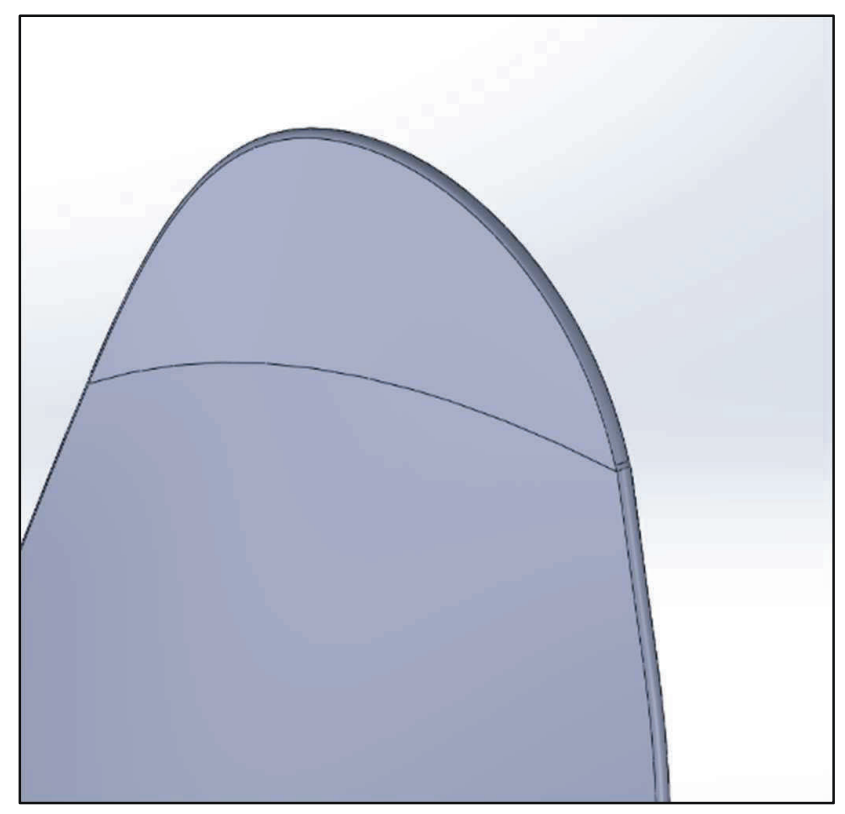

Figure 6 - Filleted blade edge

\subsection{Wageningen Hub Geometry}

The hub geometry has been designed so that it has a minimal effect on the flow around the blade and has no sharp corners to improve the quality of the mesh. The angle between the two back edges of the hub is $20^{\circ}$ and the distance between the end of the propeller and the front edge of the hub is not less than 1.5x the hub radius (see Figure 7), this is in accordance with ITTC 7.5-02-03-02.1, open water test standard (International Towing Tank Conference, 2014). The ratio of the diameter of the hub section containing the blade root to the propeller diameter $\mathrm{d} / \mathrm{D}$ is 0.167 (Oosterveld and Van Oossanen, 1975).

To achieve a high-quality mesh, the propeller has a $1 \mathrm{~mm}$ fillet added to the total blade thickness. The ends are then filleted (unstructured ANSYS meshing will not mesh properly to a fine point). It was found in the initial simulations that a good quality mesh could not be generated using sharp edged blades. ITTC 7.5-01-01-01 states "Special attention should be paid to the shaping accuracy near the leading and trailing edges of the blade section and to the thickness distributions." (International Towing Tank Conference, 2017) It would be expected that the tested model would have very fine blade edges which will result in a different flow across the propeller blade.

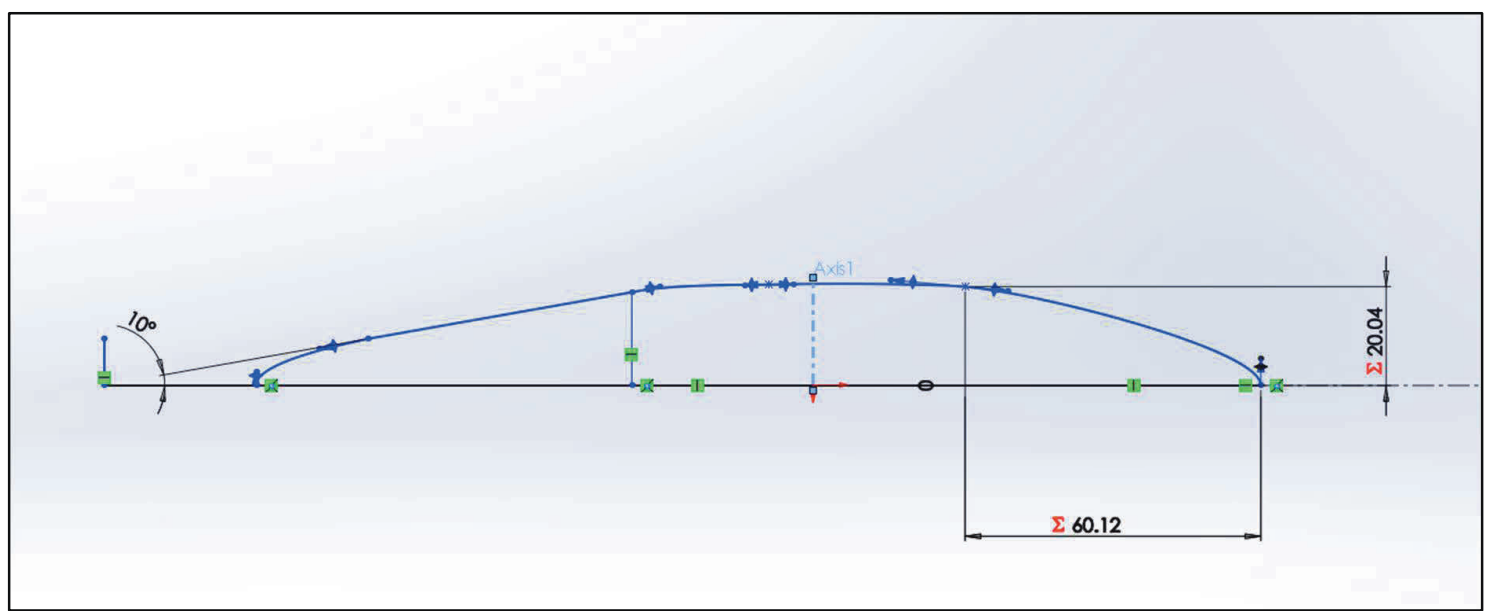

Figure 7 - Hub geometry 


\subsubsection{CLT Propeller}

The CLT propeller was generated by modifying the end $10 \%$ of the Wageningen blade, while keeping the first $90 \%$ identical. The contracted tips point towards the pressure face/front of the propeller. The CLT propeller design has got smooth transition between the original blade profile and the contracted tips. This has been done to improve the mesh quality as the method used struggles to produce high quality unstructured meshes with sharp corners (again, this was experienced during initial meshing). Figure 9 shows the CLT propeller geometry.

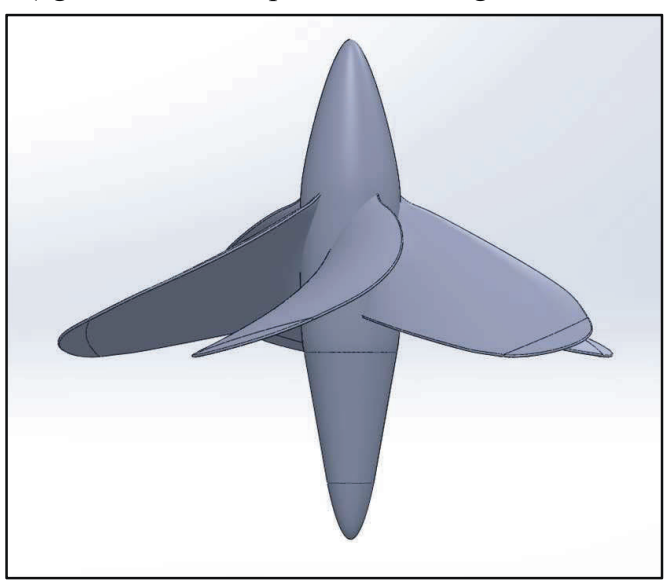

Figure 8 - Wageningen propeller model

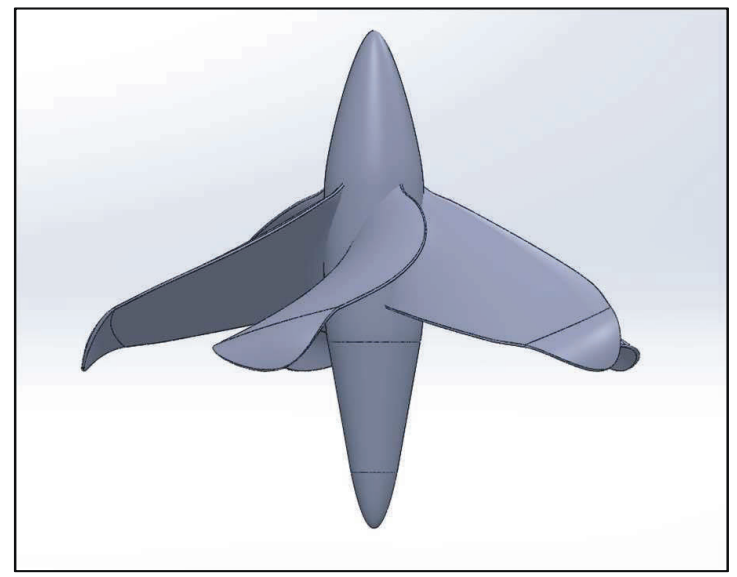

Figure 9 - CLT propeller model

\subsubsection{Domain Geometry}

The domain (the shape of the fluid to be simulated) consists of a cuboid with a cylinder inside (see Figure 10). The original Wageningen test setups have not been detailed in the available papers so the test tank geometry is not known. It has been assumed that the Wageningen propellers were tested in a tank large enough so that the walls were far enough away such that they would not to affect the propeller. Because of this, the cuboid domain has been designed to emulate this, so the walls do not to interact with the flow around the blades. Table 2 shows the size of the domain in terms of propeller diameter D.

To generate the cylindrical rotating domain, the model of the propeller was used to form a cavity in the cylindrical shape. To reduce the amount of time meshing, the cylinder has been split into helical segments with each segment containing a blade (see Figure 11).

Table 2 - Cuboid domain size in terms of propeller diameter $\mathbf{D}$

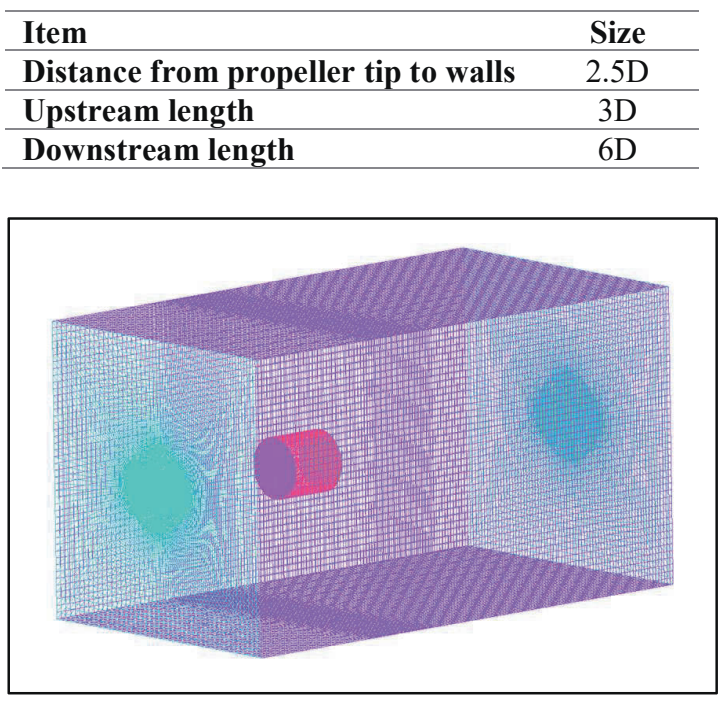

Figure 10 - Cuboid domain mesh isometric view

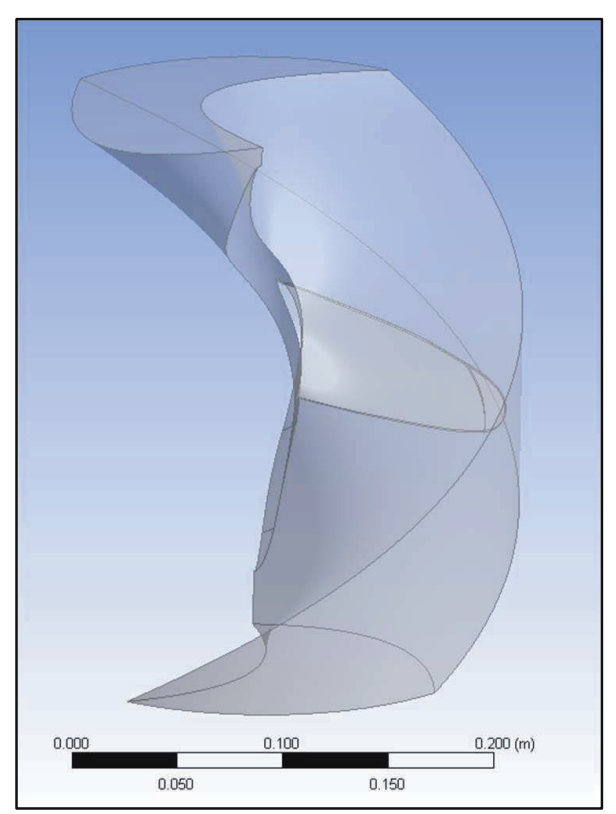

Figure 11 - Helical cylinder domain 


\subsection{Meshing}

The cuboid domain was meshed using ANSYS ICEM Meshing. A high-quality structured hexahedral mesh was used to lower the number of elements required in the domain allowing for a higher density mesh around the propeller. Figure 10 shows the cuboid domain mesh.

The rotating propeller domain was meshed using ANSYS Meshing. A fine unstructured tetrahedral mesh has been generated. Inflation layers were set on all the blade and hub surfaces. Inflation layers in a mesh are used to model the boundary layer on walls, the boundary layer is the section of flow next to a solid body where viscous forces distort the flow, it is important to model this as accurately as possible as it defines if there is turbulent or laminar flow occurring across the blade. Match control was used on the two internal faces to ensure that when the mesh is rotated it can be interfaced correctly without the results being distorted. Figure 12 shows a general view of the mesh with a section plane (a cut away in the mesh). Figure 13 shows a close-up view of the inflation layers around the leading edge of the blade, note how the layers follow the filleted blade edge smoothly. Both the Wageningen and CLT propellers were meshed using the same settings, the use of an unstructured mesh allowed both propellers to be meshed quickly and consistently. The Wageningen mesh has a total of 23 million mesh elements and the CLT mesh has 21 million.

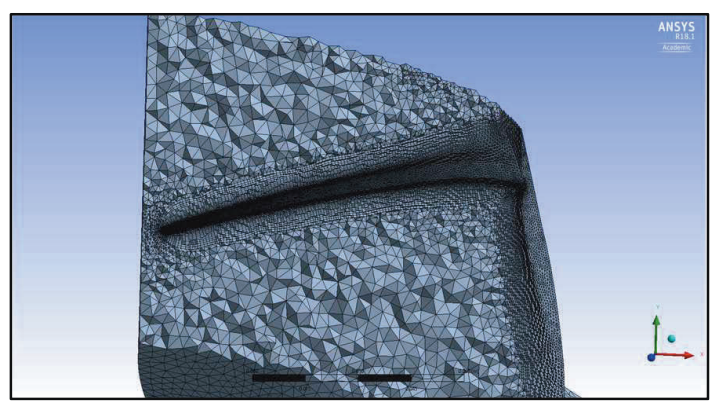

Figure 12 - Wageningen cylindrical domain mesh overview with a section plane

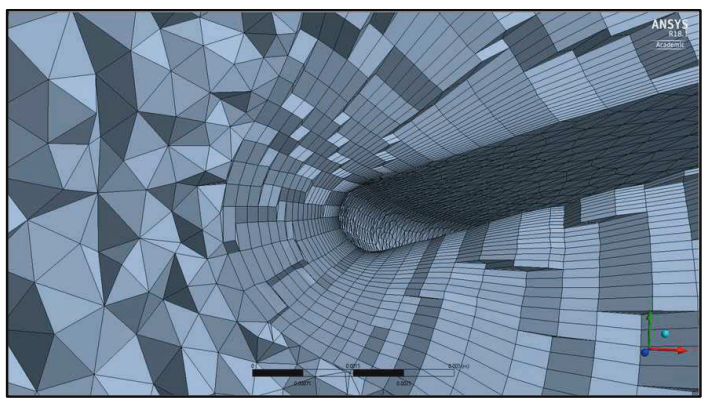

Figure 13 - Wageningen cylindrical domain mesh, focused in on the leading edge showing inflation layers

\subsection{CFD Setup}

The simulation is an open water test of the propeller, this is where the propeller is simulated by itself in a free stream of fluid. The CFD setup was designed to match the original Wageningen experimental conditions. Figure 14 shows the location of each boundary. The boundaries of the cuboid domain have been set to free slip walls to reduce the effect on the flow. The propeller blade and hub boundary has been set to smooth no slip walls. It has been assumed that the propeller blades were faired (any lumps and bumps on the surface of the blade smoothed out) and polished to eliminate frictional drag, a no slip wall with a smooth surface emulates this (ANSYS, 2018a).

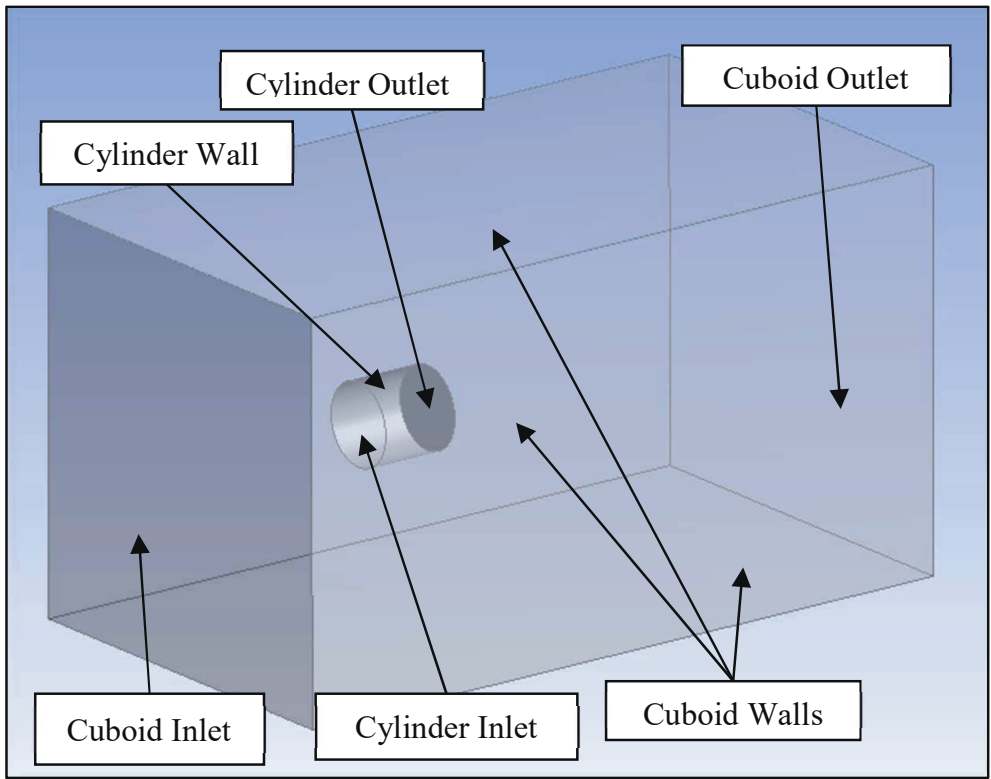

Figure 14 - Cuboid domain interface locations 
The cylindrical domain has been set to rotate at 450RPM matching the Wageningen test setup using (Van Lammeren et al., 1969). The inlet speed is set to the advance velocity $\mathrm{V}_{\mathrm{a}}$ (calculated from a chosen advance ratio (J) value using equation 1, the propeller diameter (D) and the propeller rotational speed (n)).

$$
V_{a}=\text { Advance Velocity }=J \times n \times D
$$

The residuals target was set to $1 \times 10^{-6}$ (the residuals target is the difference between each iteration of the solution solved, $1 \times 10^{-5}$ is considered good convergence and $1 \times 10^{-6}$ is very tight convergence and is required for geometrically sensitive problems (ANSYS, 2018c)). Each simulation was set to run for 1000 iterations if required, all but the smaller $\mathrm{J}$ values $(\mathrm{J}<0.5)$ converged within this, the lower $\mathrm{J}$ value runs converged after approximately 1500 iterations. The runs were solved using CFX and had double precision enabled. The CLT cases used the Wageningen CFD results for the initial conditions, each run took around 36 hours to solve.

For the CFD case to be validated using the Wageningen experimental data, the simulation needs to be running at the same Reynolds number. The Reynolds number is calculated using the chord length at $75 \%$ as the characteristic length (see equation 36) (Van Lammeren et al., 1969). Where $\mathrm{A}_{E} / \mathrm{A}_{0}$ is the blade area ratio and $\mathrm{z}$ is the number of blades.

$$
\begin{gathered}
C_{0.75 R}=\text { Chord length @ } 0.75 \mathrm{R}=2.073 \cdot \frac{A_{E}}{A_{0}} \cdot \frac{1}{Z} \cdot D \\
R e_{0.75 R}=\text { Reynolds Number @ 0.75R }=\frac{C_{0.75 R} \sqrt{V_{a}^{2}+(0.75 \pi n D)^{2}}}{v}
\end{gathered}
$$

To ensure the same Reynolds number in the CFD runs as the Wageningen tests, the advance velocity, propeller diameter, and propeller rotational speed have been kept the same. The density and temperature of the water is not stated in the Lammeren paper, nor is the atmospheric pressure (which has been assumed to be $1 \mathrm{bar}$ ). The kinematic viscosity of the water ( $\mathrm{v}$ ) the experiments were tested in has been given by Lammeren as $1.141 \times 10^{-6} \mathrm{~m}^{2} / \mathrm{s}$ (Van Lammeren et al., 1969).

ANSYS requires values for the dynamic viscosity, temperature, and density of water for the setup of the simulation. Equation 4 is used to convert from kinematic viscosity to dynamic viscosity. To find the correct water properties the kinematic viscosity of the Wageningen test water is compared to known water properties of fresh water at different temperatures. The density of water $(\rho)$ can be assumed to be approximately $999 \mathrm{~kg} / \mathrm{m}^{3}$ and the temperature to be approximately $15^{\circ} \mathrm{C}$. The dynamic viscosity of water has been calculated to be $0.0011399 \mathrm{Ns} / \mathrm{m}^{2}$.

$$
\mu=\text { Dynamic Vicsocity of Water }=\rho v
$$

\subsection{CFD Post Processing}

Once a CFD simulation completed, data from the run was used to calculate the thrust coefficient $\left(\mathrm{K}_{\mathrm{T}}\right)$, torque coefficient $\left(\mathrm{K}_{\mathrm{Q}}\right)$, and propeller open water efficiency $\left(\mathrm{\eta}_{\mathrm{O}}\right)$. (see equations 5-7)

The thrust produced by the propeller $(\mathrm{T})$ is calculated by summing the forces in the y direction on all parts of the blade and hub (the $y$ axis is in the direction of the water flow). The torque on the blade (Q) is calculated in the same way by summing the torque in the y direction for all parts of the blade and hub. These totals are used to calculate the $\mathrm{K}_{\mathrm{T}}$ and $\mathrm{K}_{\mathrm{Q}}$ coefficients using the equations below.

$$
\begin{gathered}
K_{Q}=\text { Torque Coefficient }=\frac{Q}{\rho n^{2} D^{5}} \\
K_{T}=\text { Thrust Coefficient }=\frac{T}{\rho n^{2} D^{4}} \\
\eta_{O}=\text { Open Water Efficiency }=\frac{T V_{a}}{2 \pi n Q}=\frac{J K_{T}}{2 \pi K_{Q}}
\end{gathered}
$$

\subsection{Dependency Tests}

Mesh (and domain dependency tests were carried out on the Wageningen simulation before the validation runs were completed. This is to ensure that the results computed are as accurate as possible, and that the simulated flow is not affected by the domain or the mesh quality. It was found that the domain was independent (has no effect on the flow around the blade, but the mesh was limited by the computing resources available. For the mesh tests the maximum size of the elements was changed, the settings for inflation layers across the blade were kept the same, independent tests changing the stationary and rotating domain were also carried out and it was found that the stationary domain had the largest effect on the results. 


\section{CFD Validation Case Study}

The CFD results were validated against the experimental results. Validation checks that the model is accurately simulating fluids as they would behave in the real world. Three indicators have been used to validate the simulation, propeller performance charts, blade pressure profiles, and velocity plots.

\subsection{Propeller Charts}

The Wageningen open water experimental test results are given in the form of $\mathrm{K}_{\mathrm{T}}, \mathrm{K}_{\mathrm{Q}}$, $\eta_{\mathrm{O}}$ performance charts. Propeller performance charts are non-dimensionalised characteristics of the propeller. To compare the simulation to the experimental results, the propeller performance chart for the simulated propeller needs to be generated. This is done by running the simulation at different advance ratios by varying the speed of the water. The torque coefficient, the thrust coefficient and the open water efficiency can then be calculated for each point using the method described in Section 3.4. The curves can then be plotted.

Figure 15 shows the experimental and CFD $\mathrm{K}_{\mathrm{T}}, \mathrm{K}_{\mathrm{Q}}$, and $\eta_{\mathrm{O}}$ results. It shows that the simulated propeller is showing similar $\mathrm{K}_{\mathrm{T}}, \mathrm{K}_{\mathrm{Q}}$, and $\eta_{\mathrm{O}}$ curve trends but has a lower thrust and torque coefficients, and open water efficiency. There are several potential causes for this discrepancy, the simulated blade's edges are filleted when experimental propeller would be expected to have a very fine blade edge. The simulated blade also has $1 \mathrm{~mm}$ of thickness added to it, this would present a larger frontal area to the fluid flow and in turn would increase the force pushing on the blade and therefore increase the torque on the blade. The added fillet could have reduced the area of the blade, this would reduce the amount of thrust and torque generated. The increase in torque relative to the thrust generated would result in a smaller open water efficiency. A second factor could be that the shape of the blade from $0.9 \mathrm{R}$ to the tip has not been given in the original propeller profile data. The shape of the blade tip has been interpolated using splines, this has the potential to reduce the amount of thrust generated.

Figure 16 shows the percentage error in each run (to note, the percentage error has been taken as the absolute value, the actual errors are negative). The percentage difference between the experimental test results and the CFD results increases as the $\mathrm{J}$ value increases. The main factor for this is that as the velocity increases, any errors associated with blade thickness will increase exponentially (drag is proportional to $\mathrm{V}^{2}$ ). The torque and thrust percentage errors rapidly increase between $\mathrm{J}=0.7$ and $\mathrm{J}=0.8$. Consequently, the efficiency error also increases as it is a product of both the thrust and torque.

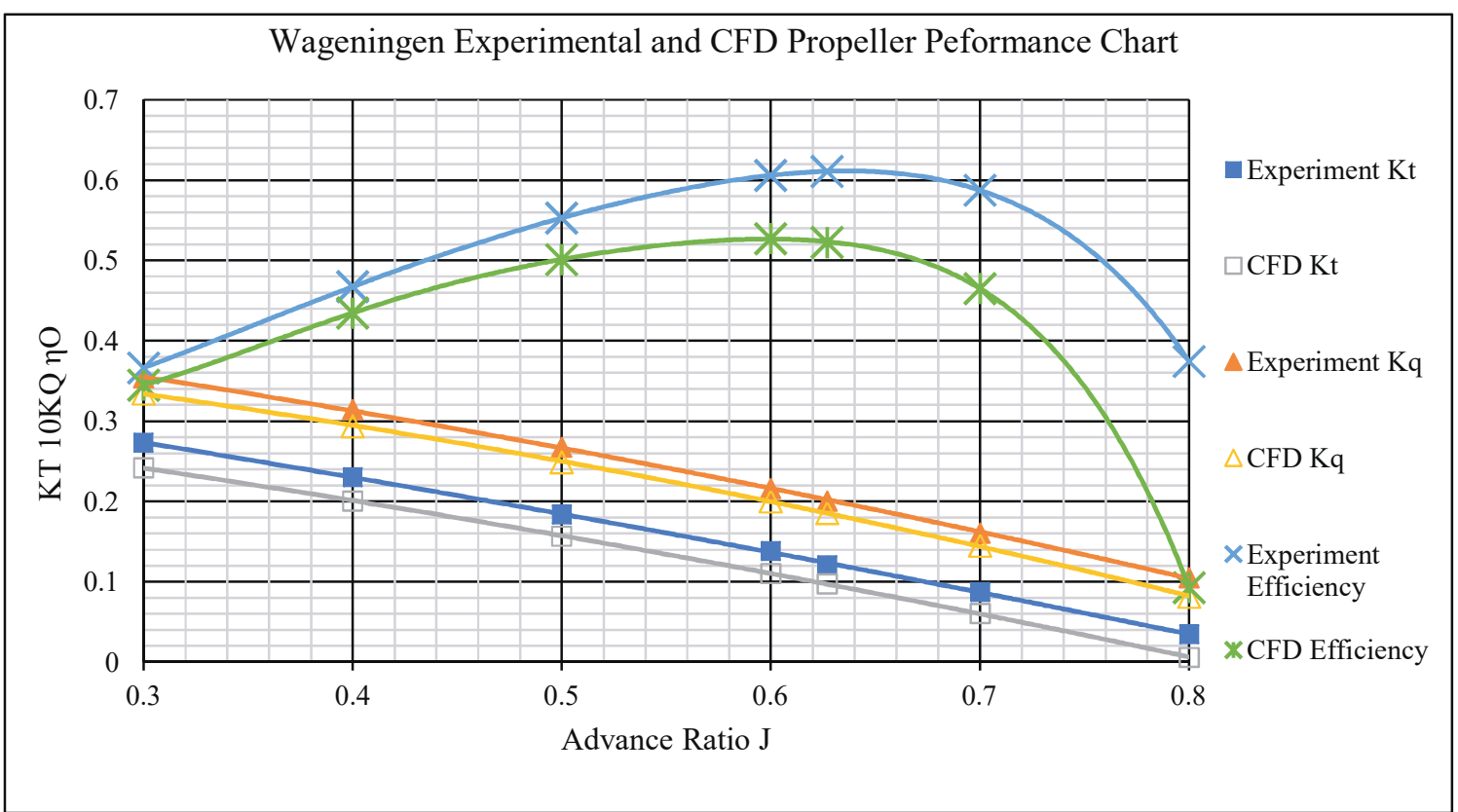

Figure 15 - Propeller performance chart for the validation case. The Wageningen results have been taken from Lammeren's “The Wageningen B-Screw Series” (Van Lammeren et al., 1969) 


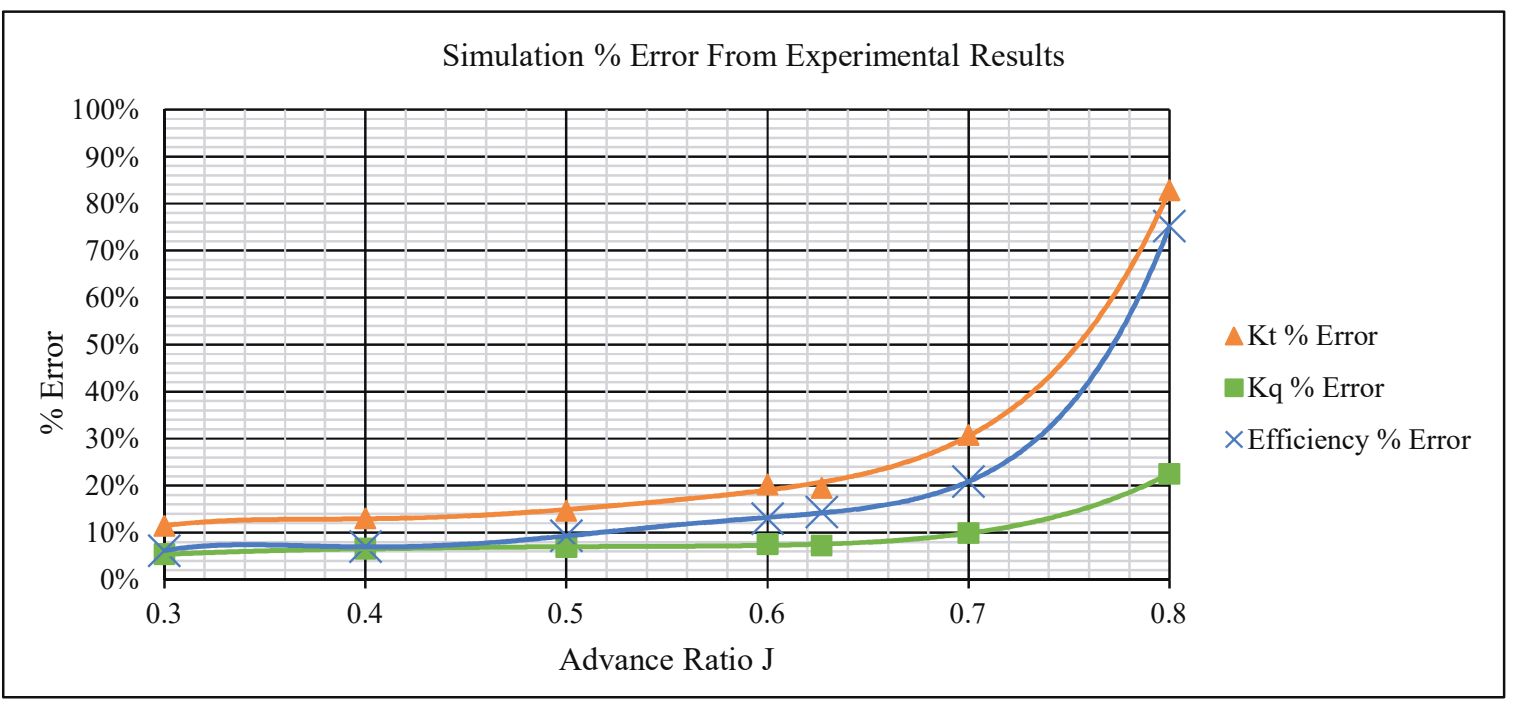

Figure 16 - Simulation \% error from experimental results

\subsection{Blade Pressure Profile}

The pressure coefficient across the blade surface is another useful validation technique. The pressure across the blade's faces at a certain radius $(\Delta \mathrm{p})$ can be used to calculate the pressure coefficient $\mathrm{C}_{\mathrm{P}}$ (see equation 8 ) (Douglas, 2011).

$$
C_{p}=\text { pressure coefficient }=\frac{\Delta p}{\frac{1}{2} \rho V_{a}^{2}}
$$

Figure 17 shows the pressure coefficient for advance ratio $\mathrm{J}=0.627$ (this $\mathrm{J}$ value has been chosen as the primary point for the validation study as it is the operational $\mathrm{J}$ value for the experimental results with the highest efficiency, this is when optimal flow is expected over the propeller so will be most sensitive to errors when simulating it) and at $0.75 \mathrm{R}$ against the $\mathrm{x}$ distance along the blade as a percentage of chord length. The graph shows the pressure distribution across the blade with the leading edge of the blade at $0 \% \mathrm{x}_{\mathrm{c}} / \mathrm{c}$. The large initial positive peak is potentially due to the force of the water on the tip of the blade. This peak is larger than expected and has probably been caused by the added thickness to the blade. The simulated pressure coefficient shows a similar shape to example blade pressure plots in Marine Propellers and Propulsion (Carlton, 2007).

Another potential cause for the positive peak is an error where the pressure and suction faces meet, CFD calculates the pressure on a face by averaging out the pressure difference between nodes, the change in pressure on a propeller between the suction face and pressure face is normally smooth and passes through zero once. This has not happened, instead the face pressure has decreased and then increased in a rapid spike at the leading edge, this error can be seen in Figure 18. The meeting between the trailing edges should also be smooth but it can be seen in Figure 17 that there are negative peaks further suggesting error in the CFD simulation. 


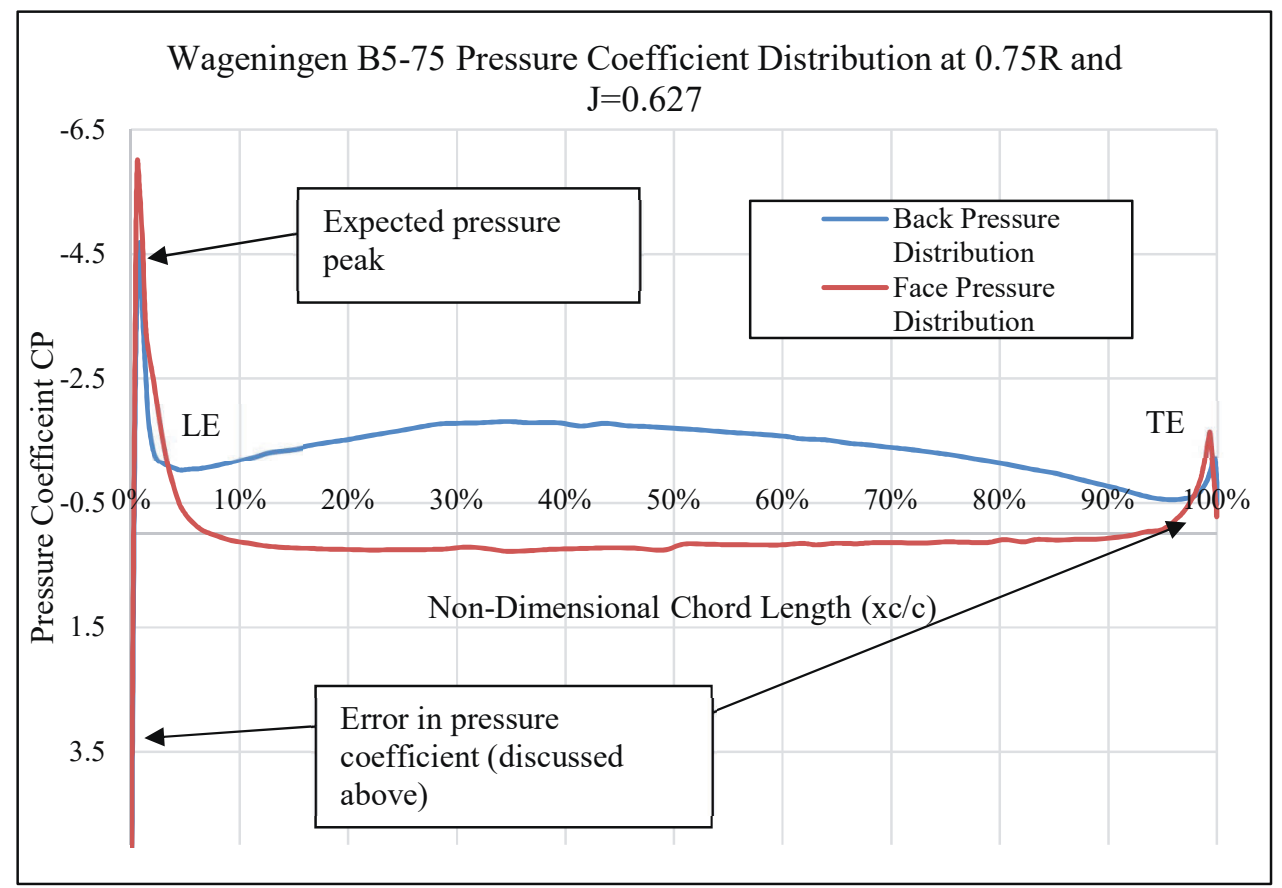

Figure 17 - Pressure coefficient against $\%$ of $x$ across the blade at $0.75 \mathrm{R}$ and $\mathrm{J}=0.627$

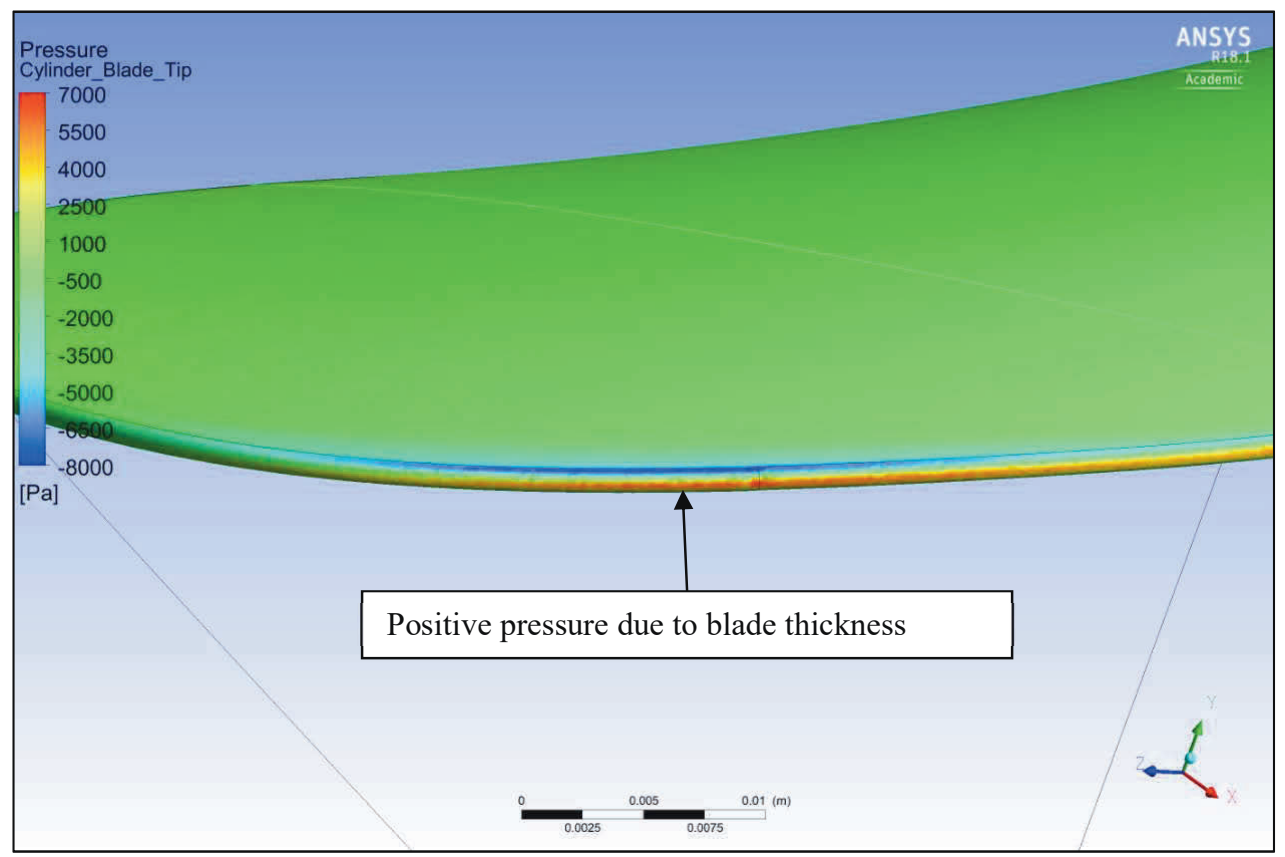

Figure 18 - Wageningen blade back pressure plot at blade tip

\subsection{Velocity Plots}

Figure 19 shows the velocity in the $y$ direction plot for $\mathrm{J}=0.627$. The water enters the propeller at the advance velocity $\mathrm{V}_{\mathrm{a}}=1.128 \mathrm{~m} / \mathrm{s}$ and exits at approximately $1.5 \mathrm{~m} / \mathrm{s}$ (an increase of $32 \%$ ). This shows that the water is being accelerated when it passes through the propeller confirming that thrust is being produced. This shows that the disturbance caused by the blade has been simulated and can be compared with the CLT propeller. 


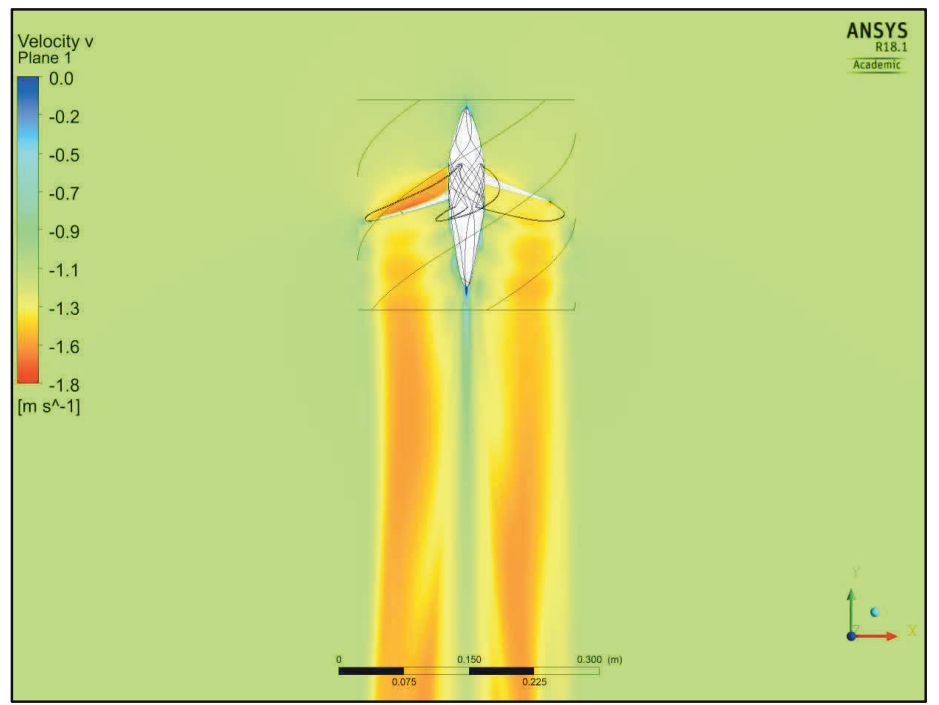

Figure 19 - Wageningen velocity in y direction plot @ $\mathrm{J}=0.627$

\subsection{Validation Summary}

Though the simulated results are not the same as the experimental results the model can still be validated as behaving like real life. The main factor causing discrepancy is that the propeller blade geometry is not identical to the original propeller used. Propellers are very geometrically sensitive so any discrepancy in shape will change the results quite considerably. As the aim of the project is to compare a potential performance improving feature the simulated propeller results can be taken as a baseline.

\section{Results}

\subsection{Performance Chart}

Figure 20 shows the propeller performance chart for the CLT and Wageningen simulation. The new design propeller is less efficient than the original Wageningen case. The operating point (the point with the greatest efficiency) of the CLT is at a lower J value than the Wageningen propeller (marked with a red point for both cases). This is characterised by the efficiency curve also dropping towards zero before the Wageningen curve.

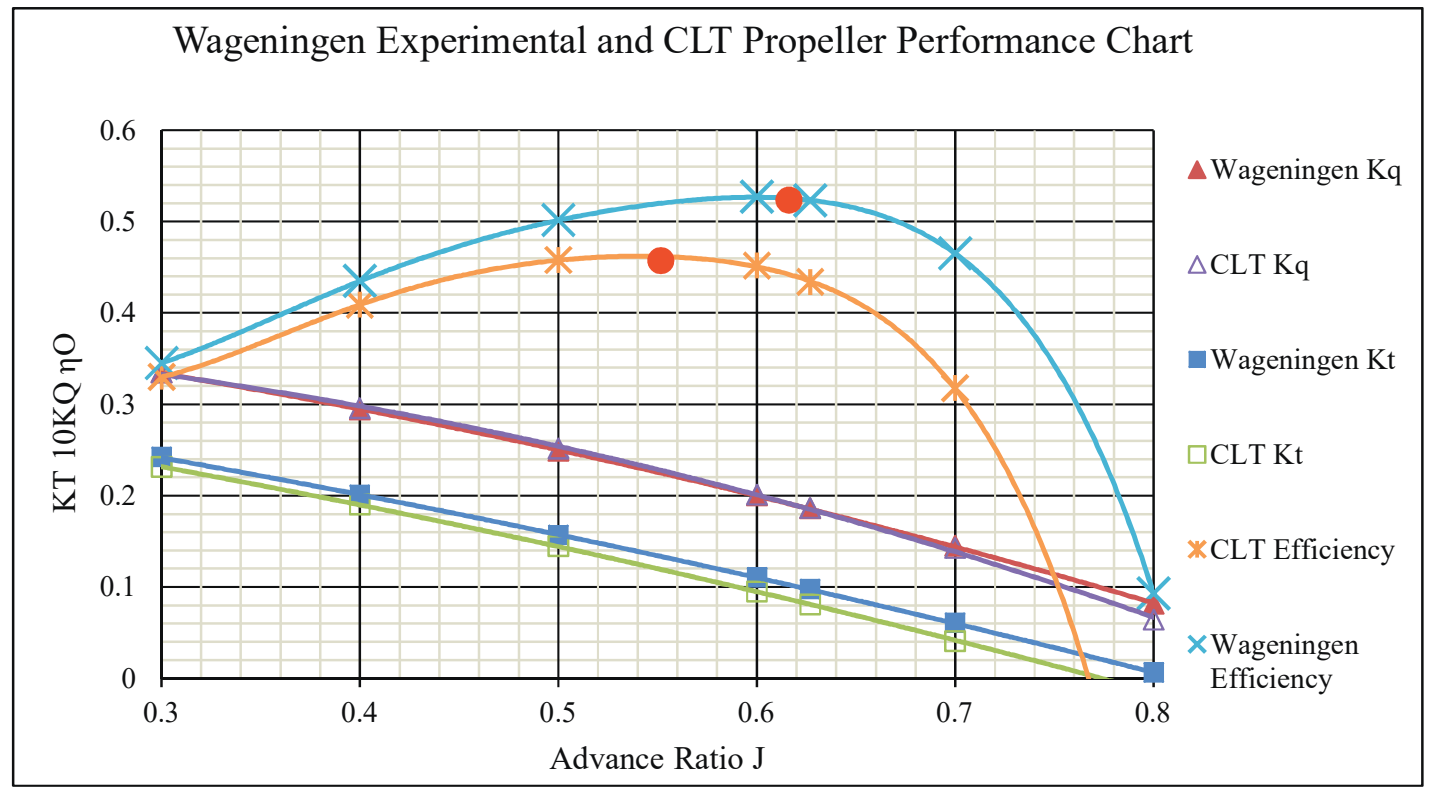

Figure 20 - Propeller performance chart for the CLT case alongside results for the Wageningen CFD case 
The torque coefficient of the CLT propeller is very similar to the Wageningen's simulation, although it decreases quicker than the Wageningen case. However, the thrust coefficient is less, this means that the CLT propeller is producing less overall thrust than the Wageningen propeller.

\subsection{Velocity Plots}

Velocity plots for both propellers at $\mathrm{J}=0.6$ can be seen in Figure 21, and Figure 22. It can be seen from the pots that the velocity downstream of the CLT propeller is much more uniform than the Wageningen simulation. The plots in the xy plane (see Figure 21) show some slight change in the disturbance of the flow of the water. Both show that the water is being accelerated at approximately the same rate with no major discrepancies between the two propellers. The plots in the zx plane at $-0.7 \mathrm{y}$ show that the flow behind the CLT propeller is very different than the Wageningen propeller. A smaller area of water is disturbed by the CLT propeller (see Figure 22), a circle of the same diameter has been plotted on both sides for reference), this clearly shows that the tips are influencing the flow narrowing the disturbed field behind the propeller.

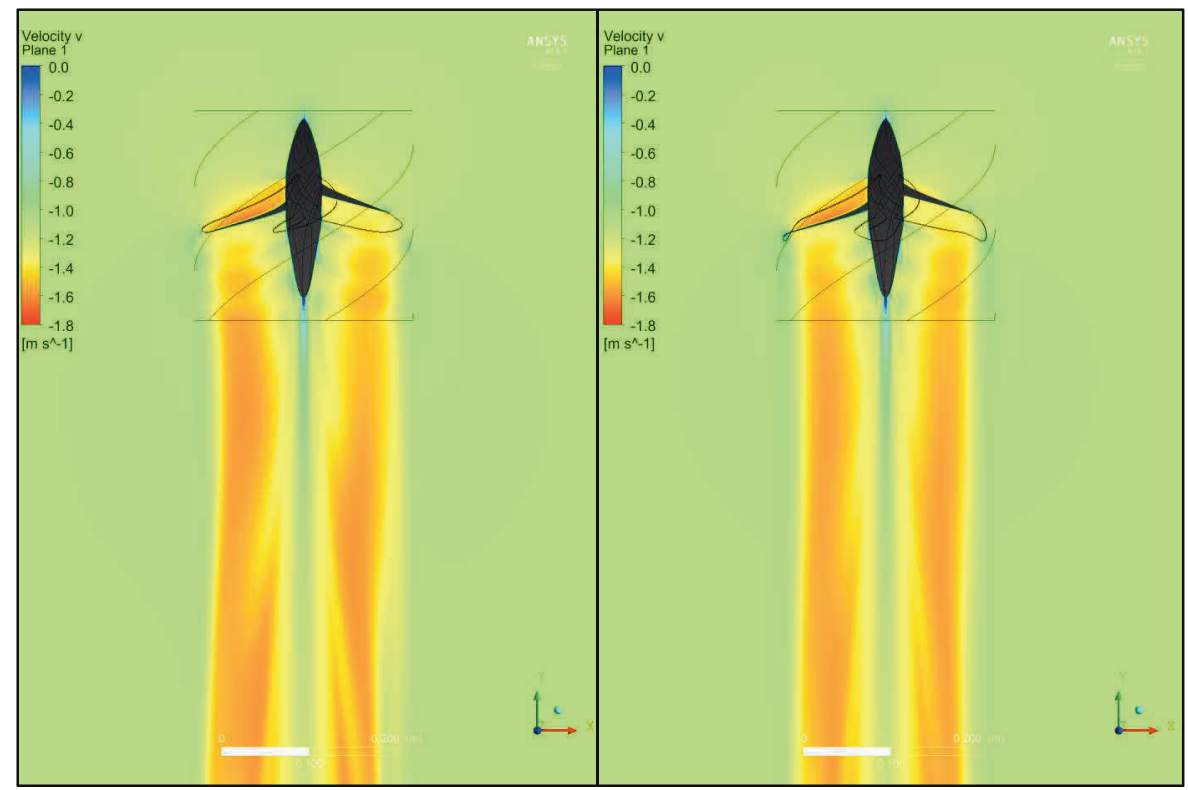

Figure 21 - Wageningen (left) and CLT (right) velocity in y direction plot @ J=0.6

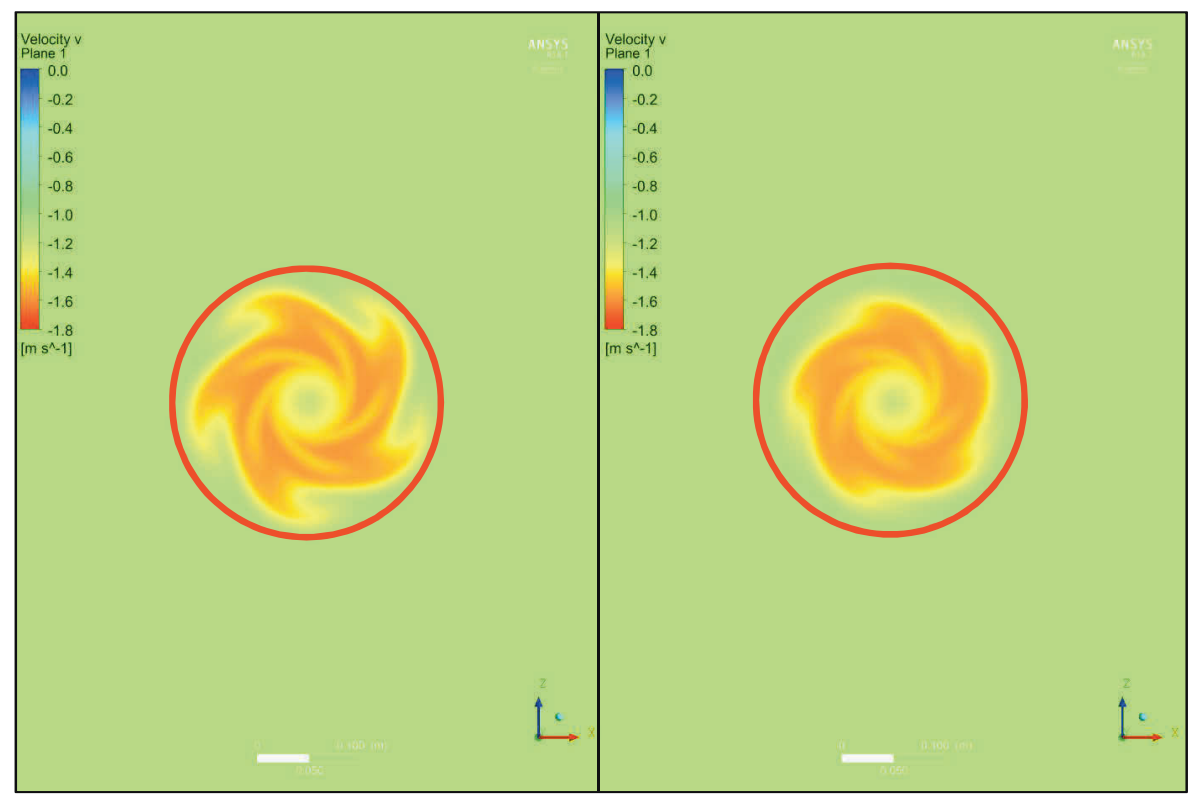

Figure 22 - Wageningen (left) and CLT (right) velocity in y direction plot @ J=0.6 looking from $y=-0.7$ with the same diameter circle plotted on both sides 


\subsection{Velocity Vector Plots}

Figure 23 shows a vector plot of velocity in the stationary frame (the stationary frame is where velocity is normalised for the rotational velocity (ANSYS, 2018b)) taken from the middle of the blade in the zx plane for the Wageningen case at $\mathrm{J}=0.4$ ( $\mathrm{J}=0.4$ has been analysed as the results are much more defined than the higher $\mathrm{J}$ values, results) It can be seen in the plot that the direction of the water is swirling from the blade tip along the suction face of the blade and it then recirculates back towards the tip again (see path highlighted in red). If the blade was able to be simulated as a sharp point it would be expected that the water would come from the pressure face of the blade (the bottom in this figure) and swirl around to the suction face of the blade.

Figure 24 shows the vector plot in the same plane for the CLT propeller and has again been zoomed in on the tip, the water travels down past the blade in the y direction with very small disturbances to the flow. The reduction in the disturbance of the water confirms that the modified tips of the CLT propeller are having the desired effect of reducing tip vortices. The flow over the CLT propeller is more uniform than the Wageningen case.

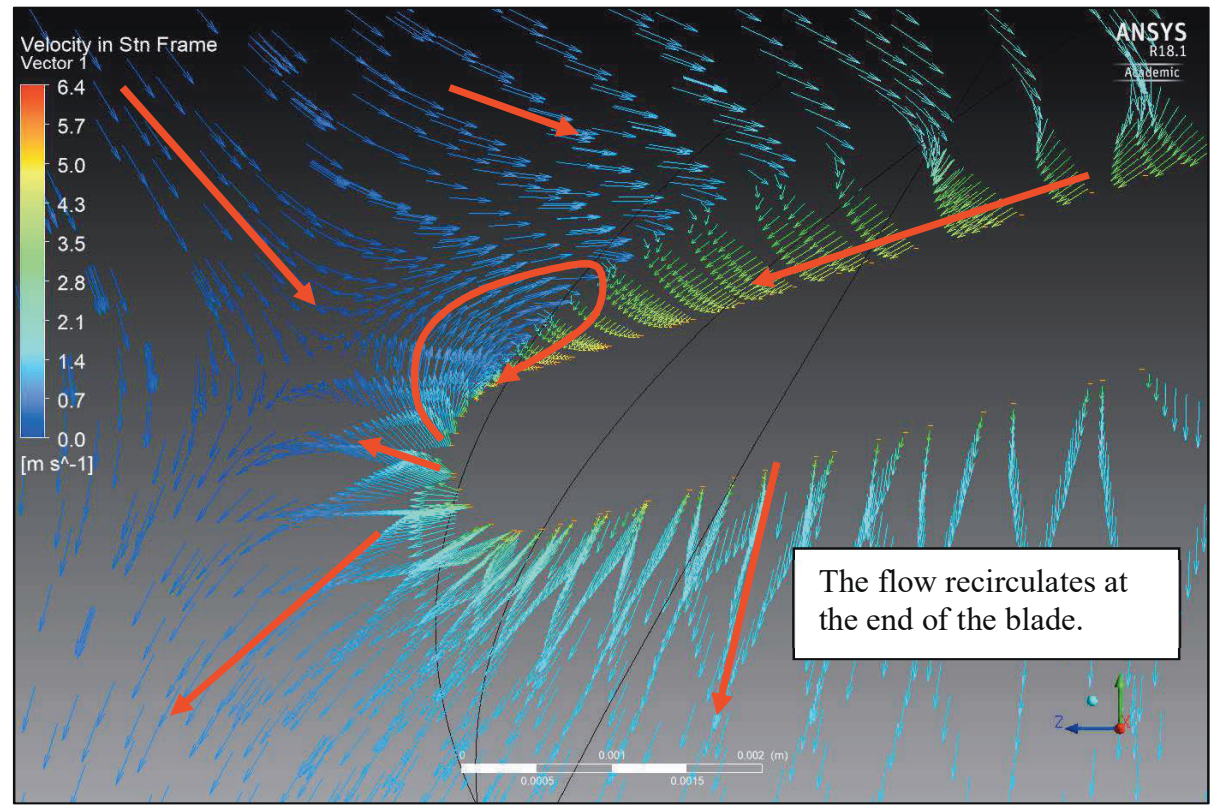

Figure 23 - Wageningen velocity in the stationary frame vector plot at the blade tip at $\mathrm{J}=0.4$. Arrows have been added to help show the direction of flow.

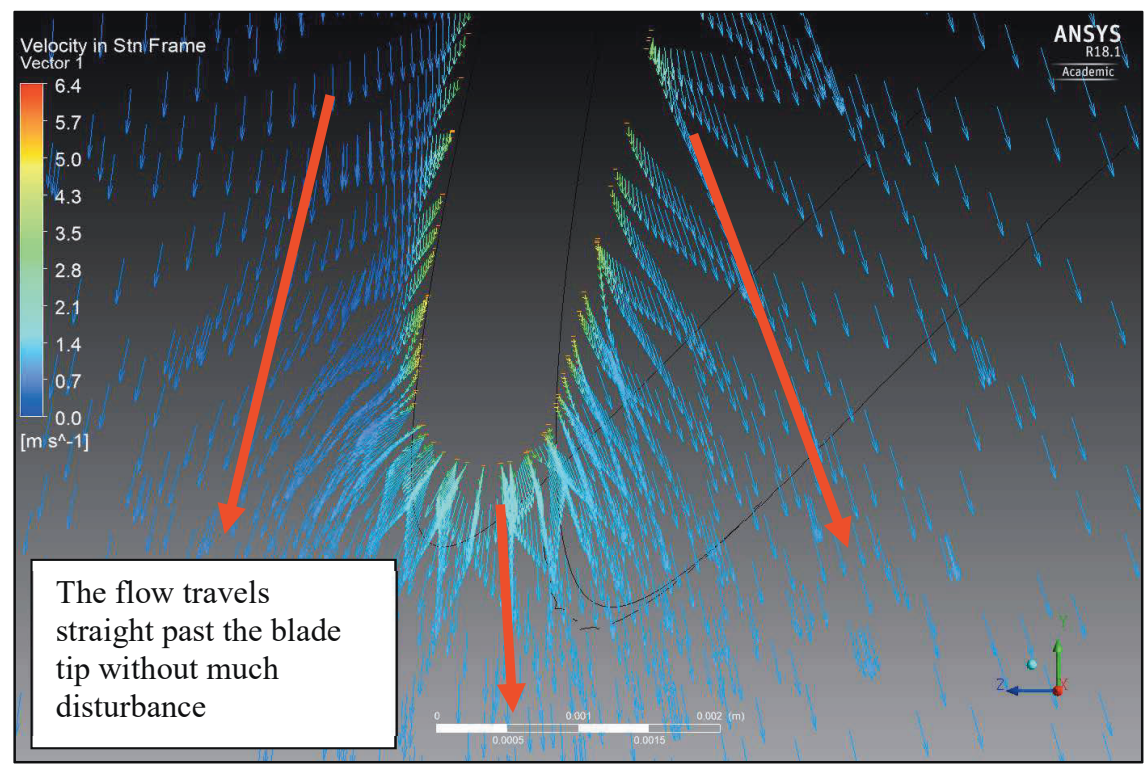

Figure 24 - CLT velocity in the stationary frame vector plot at the blade tip at $\mathrm{J}=0.4$. Arrows have been added to help show the direction of the flow. 


\subsection{Pressure Plots}

Figure 25 shows a pressure plot in the zx plane for both the Wageningen and CLT simulations at $\mathrm{J}=0.4$. It clearly shows the pressure difference in the tip between the two propellers, there is a pressure difference between the pressure and suction faces on the CLT propeller. The negative pressure on the suction face is lower on the CLT simulation ( $72 \%$ less), this will result in lower cavitation on the blade. The positive pressure on the face of the propeller is a lot larger in the CLT propeller than the Wageningen propeller ( $81 \%$ more). This is a defining characteristic of a CLT propeller.

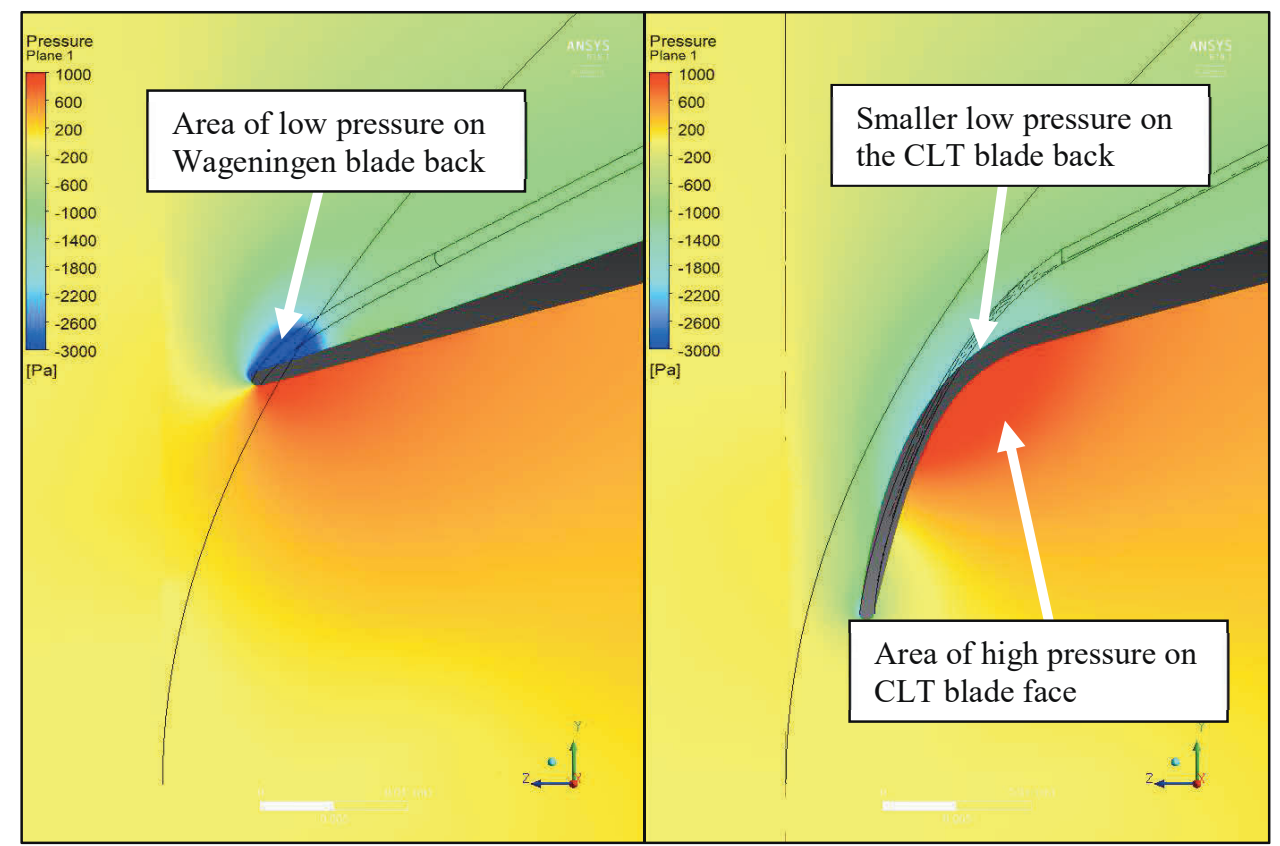

Figure 25 - Wageningen (left) and CLT (right) pressure plot at $\mathrm{J}=0.4$

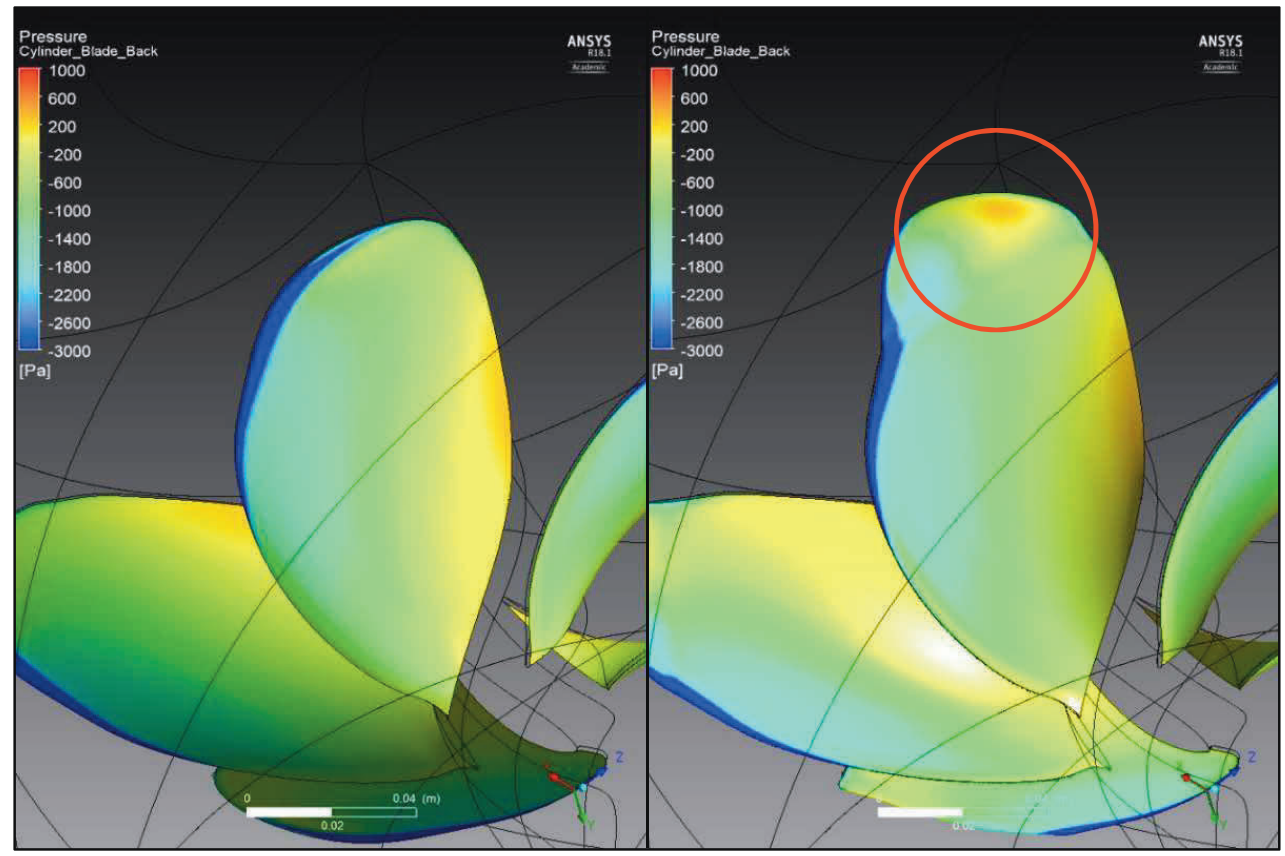

Figure 26 - Wageningen (left) and CLT (right) blade pressure plot at $\mathrm{J}=0.4$. The area of high pressure on the CLT blade has been circled in red. 
Figure 26 shows the pressure on the suction face of the propeller for both simulations (higher pressure is in red). The negative pressure on the tip of the CLT simulation is lower, as described before, however, there is a section on the blade tip where positive pressure is generated (circled in red). Positive pressure in the suction face will lead to a reduction in thrust and a drop in overall propeller efficiency (as seen in the propeller curves section). It can be noted that on the CLT simulation there is a very localised area of positive pressure towards the trailing edge of the tip. This is expected to be down to the geometry design of the contracted tip.

\section{Conclusions}

The application of a methodical CFD simulation of two propeller designs under open water test conditions has allowed underlying design principles to be directly analysed and compared. The proposed modified CLT propeller design has not improved the open water efficiency compared with the Wageningen design. However, the addition of the tips has allowed the working principles to be studied. Open water efficiency performance charts only allow so much insight into a propellers performance. Pressure profile plots and velocity vector plots can be used as an effective comparison between propeller designs showing improvements and design limitations. Geometry limitations due to the properties of unstructured meshing have caused a difference between the simulated Wageningen propeller and the experimental test results, these have been studied in detail in the validation case.

\section{Recommendations}

There is a vast array of further studies on the topic of contracted loaded tip propellers and simulating propellers using CFD that could be investigated. A few of the more notable have been discussed below:

- The CFD simulations in this investigation could be validated against experimental tank testing of the filleted Wageningen model and the proposed CLT propeller allowing the accuracy of the model to be determined.

- Access to more powerful computing resources would enable the improvement of the mesh quality allowing for propellers with shaper leading and trailing edges to be simulated. This would improve the unstructured mesh method and enable it to be applied to propeller geometry that is closer to real life.

- A range of Wageningen propellers could be simulated to derive a performance factor caused by adding the filleted edges. This would allow for the negative effect of the fillets to be considered and the CFD method to be refined further.

- The proposed simulation has only been completed on a small diameter model. A study into the scale effects of this method could be completed allowing for vessel performance to be indicted (hull wake patterns and simulations with multiple propeller arrangements would be required to do this).

- The cavitation performance improvements of the contacted tips has been mentioned, a study into the improvements made could be undertaken with validation model tests in a cavitation tunnel.

- It is hoped that in the future a CFD methodology that can be consistently applied to any propeller design could be used to quickly characterise and compare propeller of multiple designs. A database of propeller performance characteristics could be built allowing propeller designers to evaluate new designs against other models.

\section{Acknowledgements}

The author would like to thank Dr Jahir Rizvi (University of Plymouth) for supervising this undergraduate project in partial fulfilment for his BEng (Hons) Marine Technology degree.

\section{References}

ANSYS (2018a). ANSYS CFX Pre Help.

ANSYS (2018b). ANSYS CFX-Post Help.

ANSYS (2018c). CFX Modeling Guide.

Beng Yeo, K., Heng Choong, W. \& Yee Hau, W. (2014). Wageningen-B Marine Propeller Performance Characterization Through CFD.

Bertetta, D., Brizzolara, S., Canepa, E., Gaggero, S. \& Viviani, M. (2012). EFD and CFD Characterization of a CLT Propeller. International Journal of Rotating Machinery, 2012, Volume 22.

Brown, M., Sánchez-Caja, A., Adalid, J., Black, S., Pérez-Sobrino, M., Durtt, P., Schroeder, S. \& Saisto, I. (2014). Improving Propeller Efficiency Through Tip Loading.

Carlton, J. S. (2007). Marine propellers and propulsion, Oxford: Butterworth-Heinemann.

Ddouglas, J. F. (2011). Fluid mechanics, New York: Prentice Hall. 
Gaggero, S., Gonzales-Adalid, J. \& Perez Sobrino, M. (2016a.) Design of contracted and tip loaded propellers by using boundary element methods and optimization algorithms. Applied Ocean Research, 55, 102129.

Gaggero, S., Gonzales-Adalid, J. \& Sobrino, M. P. (2016b). Design and analysis of a new generation of CLT propellers. Applied Ocean Research, 59, 424-450.

Gennaro, G. 2006. Sistemar CLT Propellers. Genoa: Studio di Ingegneria Navale e Meccanica.

Gennaro, G. \& Gonzales-Adalid, J. (2012). Improving the Propulsion Efficiency by means of Contracted and Loaded Tip Propellers. Ship Operations, Management and Economics. Athens: Society of Naval Architects and Marine Engineers (SNAME).

Gonzales-Adalid, J. \& Gennaro, G. (2009). Contracted And Loaded Tip (CLT) Propeller Experience. Marine Engineers Review, 2011.

Interntational Chamber of Shipping. (2017). Shipping and World Trade [Online]. Available: http://www.icsshipping.org/shipping-facts/shipping-and-world-trade [Accessed 3/12/2017].

Interntational Maritime Organization. (2011). MARPOL - International Convention for the Prevention of Pollution from Ships, Annex VI - Regulations for the Prevention of Air Pollution from Ships. In: International Maritime Organization.

International Towing Tank Confrence, (2014). Open Water Test. Denmark.

International Towing Tank Confrence, (2017). Ship Models. Denmark.

MAN Diesel \& Turbo. (2011). Basic Principles of Ship Propulsion, Denmark.

Nguyen, T. \& Ikeda, Y. (2015). A Numerical Study on Open-water Propeller Characteristic Using CFD.

Oosterveld, M. W. C. \& Van Oossanen, P. (1975). Further Computer-Analyzed Data of the Wageningen BScrew Series. International Shipbuilding Progress, Shipbuilding and Marine Engineering Monthly.

Prakash, S. \& R. Nath, D. (2012). A Computational Method for Determination of Open Water Performance of a Marine Propeller.

SISTEMAR. (2018). CLT Propellers Theorical Fundementals [Online]. Available at: sistemar.sarein.com/CLTpropellers/Theoricalfundaments/tabid/316/language/en-US/Default.aspx [Accessed 1/05/2018].

Van Lammeren, W. P. A., Van Manen, J. D. \& Oosterveld, M. W. C. (1969). Wageningen B-Screw Series. The Society of Naval Architects and Marine Engineers. 